\title{
A educação em direitos humanos para amenizar os conflitos no cotidiano das escolas
}

Mara Regina Zluhan

Tânia Regina Raitz

\section{Resumo}

Destaca a importância da educação para favorecer a cultura da paz e da solidariedade nas escolas. Diante das diferentes violências expressas cotidianamente na sociedade, a educação em direitos humanos aparece como uma alternativa para buscar respostas aos inúmeros conflitos existentes nas escolas e no seu entorno. Ao entender-se que a escola é o germe de modificação do indivíduo, que traz em si a essência de tal modificação por meio das potencialidades que pode desenvolver, deve-se colocar o aluno no centro desse processo e pensar numa educação que possa valorizá-lo e respeitá-lo em suas diferenças e, ao mesmo tempo, mostrar que o seu futuro pode ser construído com base na cidadania.

Palavras-chave: conflitos na escola; educação em direitos humanos; proposta educativa. 


\section{Abstract \\ Human rights education for softening conflicts in daily life of schools}

This article highlights the importance of education to promote the culture of peace and solidarity in schools. Considering the different kinds of violence daily expressed in society, human rights education emerges as an alternative in the seeking of answers to the innumerable existing conflicts at school and its surroundings. From the understanding that schools are the germ of change of individuals, who bring in themselves the essence of such modification through the potentialities that one can develop, the student should be placed at the center of this process. Also, one should think of an education that values and respects the student in his/her differences and, at the same time, shows that the future can be built based on citizenship.

Keywords: conflicts at school; human rights education; educational proposal.

\section{Introdução}

A escola constitui-se como uma das mais importantes organizações sociais que constrói, por meio das relações que se estabelecem no seu interior, inúmeros princípios concernentes a uma sociedade mais justa e igualitária. Em contrapartida, tornou-se protagonista de um cenário de violências, indisciplina e afrontamentos que leva todos a buscarem respostas e estratégias que possam garantir uma convivência permeada pelos valores de respeito, diálogo e tolerância.

Para garantir a igualdade e a equidade entre os indivíduos, o Estado estabeleceu, ao longo da história, várias políticas sociais de proteção a crianças e adolescentes. Faz-se necessário buscar propostas e encaminhamentos que sustentem um fazer pedagógico que contribua para a construção de um presente mais solidário e de um futuro investido de valores de uma sociedade efetivamente mais justa e igualitária, numa ação conjunta de todos os órgãos sociais.

Se considerar-se que a escola é um espaço de circulação de culturas, diferenças e singularidades, deve-se garantir que os direitos humanos se transformem na base das relações e que a falta de entendimento, a ausência de escuta do outro, a destruição, a morte, amplamente divulgadas pelos adultos e pela mídia, se transformem em objeto de diálogo e reflexão. Dessa forma, o cotidiano escolar na atualidade deve ser apresentado numa perspectiva crítica, para que crianças e adolescentes possam manter a esperança da solidariedade, da generosidade e da justiça social, com base em práticas diárias do meio escolar, pois se entende que não basta 
ensinar os princípios da Declaração Universal dos Direitos Humanos, é necessário vivenciá-los.

\section{Educação e direitos humanos}

A comunidade escolar está diante de um novo contexto social e de um novo aluno, que é bombardeado em seu dia a dia por novidades tecnológicas, apelos consumistas e cenas de violência exacerbada. Esses e outros inúmeros elementos são refletidos na sua forma de ser, entender e relacionar-se com as pessoas e com o mundo a sua volta. Em consonância com as tecnologias, outras modificações estão presentes no cotidiano, trazidas pelos ventos da modernidade, tais como: imediatismo, superficialidade das relações, excesso de tarefas, jornada de trabalho ampliada, entre outras. Os educadores precisam estar atentos e considerar essas características na sua prática pedagógica, pois o conhecimento da realidade sociocultural da clientela escolar, suas contradições, conflitos, necessidades e desafios se constituem no elemento norteador de todo o processo educativo.

A partir desse momento, pode-se desenvolver o respeito às características e às diferenças individuais, ampliando a habilidade das relações interpessoais, de modo a se tornarem mais humanas e solidárias, possibilitando o trabalho cooperativo em função dos interesses e das necessidades dos alunos. Não se pode imaginar um projeto de educação em direitos humanos único e inflexível, que deva ser aplicado uniformemente nas diferentes realidades sociais brasileiras. Para se pensar em uma escola democrática e cidadã, é preciso ir muito além de uma prática pedagógica engessada e baseada no formalismo, na qual predominam as tarefas de planejar, executar e avaliar os conteúdos de ensino. A escola atual tem mostrado diariamente que não está mais dando conta dos desafios da contemporaneidade, por isso os educadores são chamados a repensá-la.

Para iniciar essa reflexão, segundo a qual a escola deverá incluir nos seus objetivos a convivência pacífica entre todos os seus personagens, pautada em relações de valorização do outro, de respeito e de equidade, é preciso que se destaque um documento que foi elaborado em 1948, cujas prerrogativas ainda se mantêm válidas, atuais e desafiadoras. Trata-se da Declaração Universal dos Direitos Humanos, que foi aprovada pela Organização das Nações Unidas (ONU), em dezembro de 1948.

Há que se considerar que o documento é datado, por isso não dá conta de algumas especificidades da atualidade, como as questões da sustentabilidade, do papel da mulher no mundo contemporâneo, do desenvolvimento acelerado das tecnologias, do direito à diversidade cultural que inclui as diferenças, entre outros. Como aponta Alencar (1998, p. 28):

[...] é preciso conhecer os direitos humanos não como um dogma, como um conjunto de artigos prontos, acabados, definitivos. A Declaração cinquentenária é muito boa, merece ser lida e conhecida, vivida e 
cumprida, mas tem lacunas - resultantes da época em que foi escrita, de sua temporalidade. Por isso, celebrar e valorizar a Declaração Universal dos Direitos Humanos [...] é entender que ela precisa ser acrescida, complementada, aperfeiçoada. Além de cumprida, é óbvio.

Nesse sentido, Bobbio (2004, p. 24) afirma que "o problema fundamental em relação aos direitos do homem, hoje, não é tanto o de justificá-los, mas o de protegê-los." Diante da história da humanidade e de seus diversos momentos, a educação em direitos humanos sempre se mostrou necessária e relevante, cabendo à escola o papel de sensibilizar a todos sobre a importância do respeito ao outro, das suas individualidades e diferenças, tornando-se um espaço de formação cidadã.

\section{Escola: espaço de atitudes e práticas de respeito aos direitos humanos}

A escola não pode ser somente considerada transmissora de conteúdos, mas, sobretudo, um local privilegiado de aprendizagens e vivências cidadãs e democráticas, e, quando se fala na defesa, na efetivação e na universalização dos direitos humanos, precisa-se considerar os seres humanos/alunos como seres sociais, inseridos em uma organização social, na qual devem ser asseguradas as condições para que eles se desenvolvam e venham a viver com dignidade e igualdade.

No entanto, deve-se ressaltar que o conceito de igualdade não significa que todos tenham de ter as mesmas características físicas, intelectuais ou psicológicas, tampouco os mesmos hábitos e costumes. Esse conceito está imbuído das diferenças culturais entre os povos, pois, mesmo que se trate de pessoas diferentes, continuam sendo iguais como seres humanos, apresentando as mesmas necessidades e faculdades essenciais a todos. Dallari (2004, p. 15) salienta:

O respeito pela dignidade humana deve existir sempre, em todos os lugares e de maneira igual para todos. O crescimento econômico e o progresso material de um povo têm valor negativo se forem conseguidos à custa de ofensas à dignidade de seres humanos [...].

Comparato (2007) faz uma importante reflexão acerca da autonomia do ser humano, destacando que este deve ser considerado um fim em si e não um meio para determinar a consecução de um objetivo. O autor destaca (2007, p. 22): "[...] todo homem tem dignidade e não preço, como as coisas. A humanidade como espécie, e cada ser humano em sua individualidade, é propriamente insubstituível: não tem equivalente, não pode ser trocado por alguma coisa."

Considerando, então, que o homem não pode pensar somente em si e que os seus fins devem também levar em conta os fins dos outros, ele torna-se eminentemente social e precisa dos seus pares para viver. A fragilidade humana está diretamente relacionada com a necessidade da solidariedade. Há, todavia, uma característica da pós-modernidade que 
destaca o isolamento e a individualidade, de modo que, neste momento de transição das relações sociais, os direitos humanos continuam mais indispensáveis do que nunca. Dallari (2004, p. 30) evidencia, em relação a um conjunto sistemático e harmonioso de regras, que:

Desde a Antiguidade, especialmente na Grécia, vem sendo procurada a ordem mais conveniente para a convivência humana. Aristóteles observou que a sociedade pode ser governada por um só indivíduo, por um grupo de indivíduos ou por muitos, considerando essa última forma, que está mais próxima da moderna concepção de democracia, a mais justa e conveniente.

Em face de tais regulamentações, pode-se considerar que todos os segmentos da sociedade acabam sendo persuadidos de uma função social, não somente o Estado, mas também a família, a igreja, a mídia, as organizações não governamentais (ONGs). Estes precisam revestir-se de uma consciência ética coletiva, buscando o consenso por intermédio do diálogo como forma de promover e considerar os direitos numa perspectiva que valorize as singularidades e as diferenças.

Se uma sociedade é organizada por meio de códigos, regulamentações e leis baseadas nos direitos fundamentais da pessoa humana, conjugando-se aspectos individuais e sociais inerentes a cada ser, estar-se-á favorecendo o desenvolvimento da cidadania, que é um dos fundamentos da democracia. Segundo o sociólogo Herbert de Souza (1996, p. 65), o Betinho,

[...] cidadão é um indivíduo que tem consciência dos seus direitos e deveres e participa ativamente de todas as questões da sociedade. Tudo o que acontece no mundo acontece comigo. Então eu preciso participar das decisões que interferem na minha vida. Um cidadão com um sentimento ético forte e consciente da cidadania não deixa passar nada, não abre mão desse poder de participação [....].

Diante dessa afirmação, surgem alguns questionamentos: os educadores brasileiros conseguem viver a cidadania na sala de aula, exercitando os princípios da igualdade e equidade com seus alunos? Ficam atentos para mobilizar comportamentos solidários, pois consideram que os princípios da ética e da moral são mais facilmente incorporados quando vivenciados, discutidos e refletidos no dia a dia? As políticas públicas de valorização do magistério têm destinado a devida importância ao reconhecimento social e financeiro do professor?

Sabe-se que no Brasil ainda há avanços e recuos, progressos e retrocessos quanto à implantação dos direitos de cidadania e democracia, devido a uma herança histórica que estabelece distinções, discriminações e preconceitos, não só no plano material, mas também cultural, social, racial, além do relacionado a gênero e idade. O princípio de que todos são iguais perante a lei não suprime os problemas sociais que ainda são vividos no País.

Muitos desses problemas se refletem diretamente na ação pedagógica da escola, visto que os filhos vivem e sofrem as mazelas causadas pelo 
desemprego, falta de moradia, falta de alimentação, entre tantas outras dificuldades. A escola é parte integrante da sociedade e não consegue viver apartada dela, seus muros não conseguem impedir o reflexo das desigualdades, das violências e das tragédias.

Não há uma sociedade sem conflitos, pois eles surgem naturalmente nos relacionamentos humanos, já que resultam das diferenças próprias de cada um, dos seus desejos, valores e necessidades. Por vezes, eles são até necessários, para provocar mudanças e melhorar a qualidade do convívio entre as pessoas, porém não se deve confundi-los com violência, agressividade, força e coerção.

Considerando a sua amplitude, é muito complexo definir o termo violência, em virtude das inúmeras classificações que se pode atribuirlhe, tais como: violência infantil, doméstica, contra os idosos, física, psicológica, simbólica, patrimonial, institucional, negligência e abandono. De acordo com Minayo e Assis (1994, p. 264), as violências podem ser assim definidas:

[...]para efeitos de melhor compreensão, pode-se dizer que existe uma violência estrutural, que se apoia socioeconômica e politicamente nas desigualdades, apropriações e expropriações das classes e grupos sociais; uma violência cultural que se expressa a partir da violência estrutural, mas a transcende e se manifesta nas relações de dominação raciais, étnicas, dos grupos etários e familiares; uma violência da delinquência que se manifesta naquilo que a sociedade considera crime, e que tem que ser articulada, para ser entendida, uma violência da resistência que marca a reação das pessoas e grupos submetidos e subjugados por outros, de alguma forma.

Maldonado (2004) assevera que a violência estrutural é "a mãe de todas as violências", manifestando-se por meio da ganância pelo dinheiro, da competitividade, do desejo de poder, utilizando-se de leis e instituições para manter uma situação de privilégio, desrespeitando as normas de sustentabilidade em prol do desenvolvimento atrelado a lucros excessivos, expressando-se pelo quadro de miséria, má distribuição de renda e exploração a que estão submetidos milhares de brasileiros.

No Brasil, há muitas pessoas que ainda não alcançaram sua cidadania e convivem diariamente com a violação dos seus direitos, o analfabetismo, a má distribuição das propriedades de terra, as mazelas provocadas pela dívida externa elevada, pela economia controlada em parte pelas multinacionais, pela corrupção generalizada e pelo desrespeito aos princípios básicos da humanidade.

Por diversas razões, as situações de violência passam a fazer parte da vida dessas pessoas, aumentando os índices de criminalidade, crime organizado, violência física, entre outros. Tais episódios se refletem no cotidiano da escola, por isso é preciso conhecer a comunidade na qual a escola está inserida e, considerando esse perfil, adequar a prática pedagógica para atender as necessidades e especificidades de cada grupo, posto que os conhecimentos construídos na escola devem contribuir para a formação do aluno cidadão. Paulo Freire (1983, p. 22) ajuda a pensar sob 
essa ótica quando reflete: "A leitura do mundo precede sempre a leitura da palavra e a leitura desta implica a continuidade da leitura daquele."

Ao definir as características socioeconômico-culturais da comunidade, deve-se, com o cuidado de não cair num esvaziamento pedagógico, fazer recortes de conhecimento e cultura que são essenciais para o aluno, pois é com base no conhecimento que será dada a ele a oportunidade de modificar a sua realidade. Eliot (1947, apud Forquin, 1993, p. 32) considera que:

[...] na nossa precipitação por querer que todos estudem, reduzimos nossos níveis de exigência e abandonamos cada vez mais o estudo destas matérias que servem para transmitir os elementos fundamentais de nossa cultura - ou ao menos parte da cultura que é transmissível escolarmente [...]

Nas sociedades contemporâneas, a escola é o principal local onde se estruturam as concepções de mundo e de consciência social, de consolidação de valores, de formação para a cidadania e de constituição de sujeitos sociais. De acordo com o Plano Nacional de Educação 20112020 (Brasil, 2013), para atingir esse objetivo, a educação básica deve incorporar o incentivo a estudos e pesquisas sobre as violações de direitos humanos (conflitos, violências, discriminações, entre outros temas) no sistema de ensino, desenvolvendo ações fundamentadas e procedimentos para a resolução de conflitos. É na escola que se formam valores, atitudes e práticas de respeito aos direitos humanos e, nesse contexto, a educação para diversidade é fundamental.

O cenário educacional apresenta-se com muitos contrastes, diferenças e desigualdades, no entanto, ainda se mantém como padrão aquela escola com organização rígida de espaço e tempo, estruturada por séries, turmas e bimestres, como se este modelo do passado fosse o ideal, idolatrando condutas, normas e procedimentos que não conseguem mais encarregar-se de dilemas e contradições da atualidade.

Num momento da história em que as relações interpessoais estão cada vez mais superficiais e momentâneas, a exemplo do "ficar" dos adolescentes, dos casamentos instantâneos, das amizades que num passe de mágica se transformam em ódio, encontra-se na escola um dos últimos espaços onde as pessoas precisam conviver diariamente, por um período mínimo de quatro horas.

O que significa para as crianças e os adolescentes de hoje se deparar com normas, regras e exigências institucionais? Como cumprir os horários, os prazos de entrega de atividades? Como respeitar a autoridade do professor? Como lidar com as frustrações e dificuldades naturais do dia a dia? Como não ter todos os seus desejos satisfeitos imediatamente? Por que fazer tarefas e trabalhos escolares? Afinal, são obrigações e regras que as crianças e os adolescentes não estão mais acostumados a cumprir, pois em seus lares, muitas vezes, não existem limites, obrigações e responsabilidades.

Numa sociedade globalizada, que valoriza a rapidez, a fluidez, a competitividade, encontramos uma escola que está estagnada, indo na 
contramão desse processo. La Taylle (2005) aponta duas explicações para os conflitos escolares: a primeira diz que o destaque da escola na atualidade se dá pelo entendimento de que as pessoas precisam recuperar seus laços de cordialidade, proximidade e segurança e nela se vê uma das últimas possibilidades de resgatar esses valores. De outro lado, a escola é percebida como um espaço que necessita passar por grandes transições, para poder dar conta de todas as complexidades da pós-modernidade.

Partindo do ponto de que a escola é um lugar de excelência para garantir a educação das futuras gerações, há que se refletir sobre os diversos pontos de tensão que perpassam as relações estabelecidas entre todos os seus atores, que, em alguns casos, evoluem para situações de agressividade e violência. Em comentário a tal questão, Sousa (2006, p. 33) diz que a escola necessita:

\begin{abstract}
[...] alterar os referenciais presentes nos relacionamentos interpessoais, em sua maioria pautada em modelos bélicos que constituem, no cotidiano, as expressões contínuas de prontidão para lutar, para convencer, combater, resistir, contrapor, batalhar, arguir, contestar (Maturana, 2004). Fomos educados numa cultura de guerra para escolher algumas pessoas como iguais e excluir todas as demais consideradas adversárias à minha existência. Os saberes de guerra nos impedem de reconhecer a legitimidade do outro como semelhante, ainda que diferente [...] desenvolvem em nós maneiras de convivência competitivas, que vampirizam as singularidades e produzem neuroses múltiplas.
\end{abstract}

É importante destacar que não existe uma escola com ausência de conflitos e resistências, porém não se pode concordar com o fato de que esses problemas se transformem em comportamentos e atitudes de indisciplina, agressividade ou violência. Então, é na convivência que se constroem e reconstroem valores, professores e alunos seguem em busca da compreensão do outro e do desenvolvimento da autonomia, trabalhando numa perspectiva de prevenção às violências.

\title{
Uma proposta educativa para a implantação dos direitos humanos
}

A educação em direitos humanos se configurou de forma mais estruturada no Brasil a partir da segunda metade da década de 1980, junto ao processo de (re)democratização do País. Nesse contexto, o reconhecimento e a afirmação dos direitos humanos emergiram como importantes instrumentos para a construção de uma cidadania ativa. Atualmente, vive-se sob o paradoxo de popularizar e universalizar os direitos humanos diante das cotidianas e sangrentas violações a que assistimos ao vivo na mídia e que são amplamente exploradas por todos os meios de comunicação, naturalizando-as e mostrando quão frágeis se constituem os mecanismos que zelam pela efetivação dos direitos.

Dessa forma, a escola e seus atores necessitam pensar sobre essa realidade social repleta de fragilidades, que precisam ser expostas e refletidas, a fim de que se possam implantar projetos e programas que 
estendam pontes entre as milhares de ilhas egocêntricas, que permitam visualizar para além da geografia individual. Contudo, esse ideal só será alcançado quando todos os agentes pedagógicos (escolas, igrejas, ONGs, Estado, empresas privadas, movimentos sociais, entre outros) forem capazes de pensar em uma pedagogia para os direitos humanos.

Considerando essa necessidade, surge a seguinte pergunta: como implementar uma proposta educativa para os direitos humanos na educação básica? Primeiramente, tem-se que analisar o percurso histórico de implantação de uma educação em direitos humanos, iniciando-se com uma breve revisão dos principais documentos normativos que permearam esse movimento. O grande divisor de águas foi a Declaração Universal dos Direitos Humanos (1948), que, em seu art. 26, trata especificamente do direito à educação.

Na sequência, a Conferência Mundial de Direitos Humanos, proclamada em Viena, no ano de 1993, define o objetivo da paz mundial pela educação, bem como enfatiza a importância de treinamentos e capacitações para atuar nessa área. Solicita a todos os Estados e instituições que incluam os direitos humanos, o direito humanitário, a democracia e o Estado de Direito como matérias dos currículos de todas as instituições de ensino dos setores formal e informal. A Constituição da República de 1988 discutiu o tema sob a mesma ótica, definindo em seu art. 205: "A educação, direito de todos e dever do Estado e da família, será promovida e incentivada com a colaboração da sociedade, visando ao pleno desenvolvimento da pessoa, seu preparo para o exercício da cidadania e sua qualificação para o trabalho" (Brasil, 1988).

A Lei no 9.394/1996, Lei de Diretrizes e Bases da Educação - LDB (Brasil, 1996), trouxe algumas referências que dizem respeito à educação em direitos humanos. Em seu art. 10 , o termo educação abrange "os processos formativos que se desenvolvem na vida familiar, na convivência humana, no trabalho, nas instituições de ensino e pesquisa, nos movimentos sociais e organizações da sociedade civil e nas manifestações culturais".

Com relação aos princípios, às finalidades da educação e ao dever de educar, a LDB (Brasil, 1996) define em seu art. 30, incisos IV, X e XI: a) respeito à liberdade e apreço pela tolerância; b) valorização da experiência extraescolar; c) vinculação entre a educação escolar, o trabalho e as práticas sociais. Dando continuidade, pode-se destacar o Plano Nacional de Educação em Direitos Humanos (PNEDH), que estabelece diversos programas para a promoção da educação em direitos humanos. Esse é um importante marco regulatório para a efetivação de uma prática pedagógica focada nos direitos humanos:

Esta nova perspectiva educacional de interpretação dos fenômenos sociais, culturais e políticos proposta é um estímulo à configuração de sociedades democráticas abertas, pautadas em uma nova consciência capaz de compreender a condição do mundo humano, definindo novos caminhos para a construção da cidadania. Este processo resgata as duas esferas do ser humano: o conhecimento racional, empírico e 
técnico de um lado, e o simbólico, poético, mágico e mítico de outro. É no entrelaçamento destas duas dimensões que a educação para a cidadania encontra seu ancoradouro e sua potencialidade em relação ao futuro. (Brasil, 2003, p. 12).

O PNEDH apresentou meios de concretização da educação em direitos humanos, possibilitando o início de um trabalho sistemático e institucionalizado a fim de fomentar uma educação voltada para a promoção da igualdade, da justiça, da solidariedade, da cooperação, da tolerância e da paz. O PNEDH exibe, inicialmente, seus objetivos e linhas gerais de ação para, em seguida, distribuir as metas e ações propostas em cinco eixos: educação básica; educação superior; educação não formal; educação dos profissionais dos sistemas de justiça e segurança; e educação e mídia. O documento aponta os seguintes princípios para a educação básica (Brasil, 2003, p. 17):

- A educação básica, como um primeiro momento do processo educativo ao longo de toda a vida, é um direito social inalienável da pessoa humana e dos grupos socioculturais.

- A educação básica exige a promoção de políticas públicas que garantam a sua qualidade.

- A construção de uma cultura de direitos humanos é de especial importância em todos os espaços sociais. A escola tem um papel fundamental na construção dessa cultura, contribuindo para a formação de sujeitos de direitos, mentalidades e identidades individuais e coletivas.

- A educação em direitos humanos, sobretudo no âmbito escolar, deve ser concebida de forma articulada ao combate do racismo, sexismo, discriminação social, cultural, religiosa e outras formas de discriminação presentes na sociedade brasileira.

- A promoção da educação intercultural e de diálogo inter-religioso constitui componente inerente à educação em direitos humanos.

- A educação em direitos humanos deve ser um dos eixos norteadores da educação básica e permear todo o currículo, não devendo ser reduzida a disciplina ou a área curricular específica.

Diante da relevância do Plano Nacional de Educação em Direitos Humanos, passa-se a elencar algumas das suas linhas de ação (Quadro 1).

A questão que surge quando se reflete sobre esse tema é muito comum: será realmente possível pensar em uma educação para os direitos humanos em uma sociedade tão dividida, individualista e pautada nos princípios neoliberais? Talvez um dos caminhos possa ser reconhecido por meio das recomendações de Paulo Freire (1978), quando diz que a educação deve ser dialógica, levando à colaboração, organização, síntese cultural e reconstrução do conhecimento. Considerando que tal abordagem corrobore para o desenvolvimento da justiça e da paz, uma pessoa só pode reconhecer seus próprios direitos a partir do momento em que consegue perceber os direitos dos outros e, então, terá de considerar que pobres, 
excluídos, desempregados, entre outras categorias, não são passíveis de intolerância e discriminação. Alencar (1998, p. 54) afirma que a educação em direitos humanos

[...] considera o educando como centro do processo educativo e, indutiva, vai da prática à teoria para retornar e melhor qualificar a prática. Parte de casos concretos e utiliza recursos como casos, pesquisas, desenhos [....] e, sobretudo, valoriza a narrativa oral e existencial dos educandos. Ela se direciona do local para o internacional; do pessoal ao social; do detalhe ao geral; do fato ao princípio; do biográfico ao histórico. O educador não educa, ajuda a educar e, ao fazê-lo, predispõe a reeducação. E todo o processo educativo tem como ponto de partida e de chegada a ação dos sujeitos educados (educandos e educadores) na transformação da realidade em que se inserem.

\section{Quadro 1 - Plano Nacional de Educação em Direitos Humanos - Linhas de Ação}

Universalizar o acesso e a permanência de crianças e adolescentes na escola com equidade e qualidade.

Estimular experiências de interação da escola com a comunidade que contribuam para a formação da cidadania democrática.

Apoiar e incentivar as diversas formas de acesso e inclusão dos estudantes com necessidades educacionais especiais.

Inserir, efetivamente, a leitura e a discussão do Estatuto da Criança e do Adolescente - ECA (Lei $\mathrm{n}^{\circ}$ 8.242/91) nos projetos pedagógicos a serem elaborados nas escolas.

Desenvolver projetos culturais e educativos de luta contra a discriminação racial, de gênero e outras formas de intolerância.

Apoiar e incentivar a inserção das questões do meio ambiente no currículo escolar.

Trabalhar questões relativas aos direitos humanos e temas sociais nos processos de formação continuada de educadores, tendo como referência fundamental as práticas educativas presentes no cotidiano escolar.

Promover e produzir materiais pedagógicos orientados para a educação em direitos humanos, assim como sua difusão e implementação.

Incentivar programas e projetos pedagógicos, junto aos sistemas de ensino, que busquem combater a violência doméstica com crianças, adolescentes, jovens e adultos.

Apoiar e incentivar a produção e manifestação cultural dos jovens.

Garantir a formação inicial e continuada aos profissionais da educação básica na perspectiva dos direitos humanos.

Promover experiências de formação dos estudantes como agentes promotores de direitos humanos.

Introduzir a perspectiva da educação em direitos humanos como componente da formação inicial dos educadores.

Fonte: PNEDH (Brasil, 2003, p. 18). 
Nessa perspectiva, as propostas pedagógicas que orientam a cultura da paz, do respeito e da equidade devem ser implantadas inter e transdisciplinarmente, integrando os planejamentos de todas as disciplinas, de forma que associem esses valores ao cotidiano da sala de aula, imbricados nos objetivos conceituais, procedimentais e atitudinais de cada disciplina. Pode-se buscar em Vygotsky (1984) elementos para pensar a educação em direitos humanos, pois ele relaciona o desenvolvimento cognitivo do aluno ao contexto social e cultural. Dessa forma, os processos mentais superiores (pensamento, linguagem, comportamento volitivo, atenção consciente, memória voluntária etc.) têm origem nos processos sociais. Assim, não é por meio do desenvolvimento cognitivo que o indivíduo se torna capaz de socializar, é na socialização que se dá o desenvolvimento dos processos mentais superiores.

Nesse processo, o professor exerce o papel de mediador, favorecendo a construção/reconstrução do conhecimento, dos significados que são transmitidos pelo grupo cultural, por intermédio das reflexões, das práticas sociais e da utilização de instrumentos, signos e linguagens empregados para interpretar o mundo e tornar o aluno mais independente (Vygotsky, 1984). Cabe ao professor estabelecer conexões entre os conceitos científicos e o cotidiano, respaldado nos princípios dos direitos humanos, mediando o conhecimento num processo de descoberta, produção, troca e cooperação.

Na perspectiva de um programa educativo que valorize o cumprimento dos direitos humanos, as situações de conflito no meio escolar devem ser explicitadas, vividas e superadas de forma democrática, mediante discussão, diálogo e acordo. É importante que haja possibilidade de expressão das diferenças e que a vivência democrática favoreça a pluralidade. Fagherazzi (2002) afirma que a vivência democrática supõe a "con-vivência", a sensibilização aos valores voltados para a igualdade de direitos e oportunidades. É importante perceber que, na atividade cotidiana, se vive numa rede de relações que nos torna dependentes uns dos outros.

Já Sacristán e Gomes (1998) assinalam que certas unidades de ensino reproduzem e transmitem alguns valores vivenciados na sociedade, tais como o individualismo, a competitividade, a falta de solidariedade, a desigualdade "natural" de resultados, em função de capacidades e esforços individuais. Diante disso, devem-se compreender os conhecimentos, as capacidades, as disposições dos alunos ante as diversas situações no cenário social, a fim de poder socializar às novas gerações a atenção e o respeito pela diversidade.

Todos esses apontamentos podem parecer complexos, quando se leva em conta que muitos alunos convivem com dramas sociais e familiares, são tratados com hostilidade, são rejeitados, sentem-se solitários ou estão cansados pelo acúmulo de responsabilidades e tarefas que precisam executar, de sorte que demonstram seus problemas por meio do comportamento inadequado na escola. Portanto, a simples menção 
a tais temáticas não garante que os conceitos serão apreendidos e que haverá modificação de comportamento. O ensino não termina quando o conteúdo é recebido, mas é o começo do cultivo de uma mente, de forma que o que foi semeado crescerá.

Para que haja aprendizagem, é necessário que haja atividade mental, isto é, aprender é agir, pensar e refletir. É fundamental ajudar o aluno a incorporar os novos conhecimentos de forma ativa, compreensiva e construtiva, promovendo as suas capacidades cognoscitivas, que são as suas energias mentais, ativadas e desenvolvidas no processo de ensino (exercitação dos sentidos: observação, percepção, compreensão, generalização, raciocínio, memória, linguagem, motivação). Desse modo, toda aprendizagem é pessoal, "ninguém aprende pelo outro".

Quais recortes do conhecimento a escola deve fazer para definir os conceitos científicos e as competências para o desenvolvimento de atividades de aprendizagem significativa, geradoras de novas aprendizagens e propiciadoras da formação do cidadão consciente e agente de mudanças? Machado (2006, p. 81), nesta passagem, ensina-nos que:

[...] mais do que dar a matéria, mais do que "transmitir conhecimento", ao professor compete, precipuamente, despertar o interesse dos alunos, fazê-los querer, desejar, ter vontade, em outras palavras, estimular e semear projetos. Toda matéria, todo conhecimento é pretexto. O que vale efetivamente são as metas que perseguimos, os valores que nos guiam $[\ldots]$.

Para dar conta dessa tarefa, Tavares (2012) explica que é necessária a elaboração de um saber docente sobre os direitos humanos, que se constitui com a relação entre o saber curricular (refere-se à flexibilidade do currículo para agregar as questões relativas aos direitos humanos), o saber pedagógico (trata-se de estratégias e recursos que serão utilizados para transversalizar os conteúdos da disciplina com os temas dos direitos humanos) e o saber experiencial (que trata da vivência dos valores em todos os espaços escolares).

Conforme Tavares (2012), para que a educação em direitos humanos se concretize, o educador não pode permanecer no seu papel de mero transmissor de conteúdos, de executor de seu plano, mas deve assumir alguns procedimentos no seu fazer pedagógico, de modo que:

a) acredite no que faz, pois sem a convicção de que o respeito aos direitos humanos é fundamental para todos, não é possível despertar os mesmos sentimentos nos demais;

b) eduque com o exemplo, porque de nada adianta ter um discurso desconectado da prática ou ser incoerente exigindo dos demais determinadas atitudes que a própria pessoa não cumpre;

c) desenvolva uma consciência crítica com relação à realidade e um compromisso com as transformações sociais, já que o propósito desse tipo de educação é formar sujeitos ativos que lutam pelo respeito aos direitos de todos. 
Nesse sentido, é fundamental que o educador tenha oportunidade de participar de cursos de formação inicial e continuada, voltados para a difusão dos ideais e valores dos direitos humanos, da democracia e da cidadania como eixos norteadores de toda e qualquer prática escolar. É importante ressaltar que de nada adianta a escola se preocupar com uma educação em direitos humanos, com a formação dos docentes, se ela não vive cotidianamente práticas democráticas e cidadãs com os alunos, pais e comunidade em geral. Por isso, as instituições escolares necessitam refletir sobre seus pressupostos pedagógicos, para superar práticas tradicionais de educação, pautadas na obediência e no medo, para elaborar uma nova cultura, que significa criar, influenciar, compartilhar e consolidar mentalidades, costumes e atitudes, hábitos e comportamentos baseados nos princípios dos direitos humanos - não mediante a imposição desses valores, mas por meios democráticos de construção e participação que possibilitem a experiência de tais direitos.

Por meio da articulação dessas experiências, destaca-se a possibilidade de desenvolver uma percepção emancipadora e transformadora da realidade, sendo possível sensibilizar-se, indignar-se, comprometer-se e atuar perante as práticas sociais. Continuando o estudo sobre a efetivação de uma educação em direitos humanos na educação básica, Tavares (2012) lista alguns princípios relacionados com os aspectos conceituais dessa prática.

a) O primeiro deles é o princípio da integração, que defende que temas e conteúdos de direitos humanos façam parte integral de conteúdos e atividades do currículo e dos programas de estudo.

b) O segundo é o princípio da recorrência, segundo o qual o aprendizado em direitos humanos é obtido na medida em que é praticado uma e outra vez em circunstâncias diferentes e variadas.

c) O princípio seguinte é o da coerência, pois o êxito do aprendizado é reforçado quando se cria um ambiente propício para seu desenvolvimento. A coerência entre o que se diz e o que se faz é parte importante nesse ambiente.

d) O quarto princípio é o da vida cotidiana. Como a educação em direitos humanos está estreitamente vinculada à multiplicidade de situações da vida cotidiana, é relevante que o educador resgate essas situações e momentos em que os direitos humanos estão em jogo.

e) O princípio da construção coletiva do conhecimento aparece como o quinto, enfatizando a importância de que as pessoas analisem, grupalmente, a informação recebida sobre direitos humanos, deixem de ser meros receptores passivos e se tornem produtores de conhecimento.

f) O último princípio é o da apropriação. Por meio dele, a pessoa apropria-se do discurso recebido, recriando-o, ou seja, reelabora as várias mensagens, traduzindo-as num discurso próprio, do qual toma plena consciência e que orienta as atuações da sua vida. 
Assim, Candau (1999, p. 18) aponta outra estratégia metodológica que pode ser utilizada na educação em direitos humanos - a oficina pedagógica:

\begin{abstract}
Uma estratégia metodológica é privilegiada: a oficina pedagógica, como espaço de construção coletiva de um saber, de análise da realidade, de confrontação e intercâmbio de experiências, de exercício concreto dos direitos humanos. A atividade, a participação, a socialização da palavra, a vivência de situações concretas através de sociodramas, a análise de acontecimentos, a leitura e discussão de textos, a realização de vídeodebates, o trabalho com diferentes expressões da cultura popular, etc, são elementos presentes na dinâmica das oficinas. O desenvolvimento das oficinas, em geral, se dá através dos seguintes momentos básicos: aproximação da realidade/sensibilização, aprofundamento/reflexão, construção coletiva e conclusão/compromisso. Para cada um desses momentos é necessário prever uma dinâmica adequada para cada situação específica, sempre tendo-se presente a experiência de vida dos sujeitos envolvidos no processo educativo.
\end{abstract}

Nessa linha, Candau (1999) prossegue dizendo que a escola pode privilegiar a discussão de temas como desemprego, violência estrutural, saúde, educação, distribuição da terra, concentração de renda, dívida externa e dívida social, pluralidade cultural, segurança social, ecologia, entre tantos outros. Do ponto de vista pedagógico, admite a transversalidade, mas privilegia a interdisciplinaridade e enfatiza "temas geradores". Trabalha as dimensões sociocultural, afetiva, experiencial e estrutural do processo educativo na perspectiva da pedagogia crítica e assume o ponto de vista psicopedagógico, num construtivismo sociocultural.

Entretanto, tem-se que considerar que a educação em direitos humanos não se resume a padronizações didáticas, temáticas ou metodológicas, mas consiste na comunhão em torno de certos princípios e objetivos - que não se limitam a temas geradores de aula -, que devem se constituir em eixos norteadores de toda prática escolar e em princípios inspiradores de ações educativas.

Para isso, faz-se necessário conhecer as inúmeras modificações percebidas em crianças e adolescentes da atualidade. Com frequência, os adultos afirmam que eles já "nascem falando" e vão desenvolvendo uma compreensão ampla das coisas que lhes cercam. Por outro lado, a tarefa de educá-los está cada vez mais complexa, pois facilmente tornam-se indisciplinados e sem limites. Os professores, por sua vez, afirmam que sentem saudades daquela escola do passado, na qual os alunos eram disciplinados e respeitavam ordenadamente as regras estabelecidas. Porém, com o avanço da ciência, das pesquisas e da tecnologia, passou-se a conhecer muito melhor o desenvolvimento infantil e vários elementos foram substituindo a forma de educar, muito diferentes da submissão, da disciplina e do formalismo de tempos passados.

Por outro lado, novas políticas públicas foram implantadas para dar conta de todas as modificações da infância e adolescência, exigindo que 
os paradigmas educacionais estejam em constante processo de análise e revisão, a fim de atender as especificidades dessa nova geração. Diante de tantos avanços, em todas as áreas do conhecimento, não se pode aceitar que tenha havido uma regressão no papel educativo da escola. O que talvez esteja faltando é um certo equilíbrio entre as coisas boas do passado que devem ser mantidas e os ranços que devem ser descartados, para que se dê lugar a novas possibilidades de ver e viver o mundo.

Esse saudosismo docente acaba mascarando uma série de barbáries que eram cometidas contra crianças e adolescentes. Basta fazer um breve retrospecto na história para lembrar a forma como as crianças eram tratadas por seus pais e professores. As escolas eram regidas por severos códigos de conduta e, ao menor sinal de transgressão, os castigos eram aplicados (orelha de burro, palmatória, cheirar parede, ajoelhar no milho, cadeira do pensamento, humilhações etc.).

\section{Quadro 2 - Ordenamentos Legais que Constituem as Políticas de Educação, Prevenção, Atenção e Atendimento em relação às Violências}

\section{Declaração Universal dos Direitos Humanos \\ Declaração Universal dos Direitos da Criança}

Constituição Federal de 1988

Constituição do Estado de Santa Catarina

Estatuto da Criança e do Adolescente (ECA), Lei no 8.069, de 13 de julho de 1990

Lei de Diretrizes e Bases da Educação Nacional (LDB), Lei nº 9.394, de 20 de dezembro de 1996

Programa Nacional de Direitos Humanos (PNDH-3), instituído pelo Decreto Presidencial no 7.037, de 21 de dezembro de 2009

Programa Mundial para a Educação em Direitos Humanos (2004)

Plano Nacional de Educação em Direitos Humanos (PNEDH) (2009)

Lei Estadual no 14.651/2009, que institui o programa de combate ao Bullying

Resolução n 4/2010, que define as diretrizes curriculares nacionais gerais para a educação básica

Resolução no 7/2010, que fixa as diretrizes curriculares nacionais para o ensino fundamental de nove anos

Lei $n^{\circ} 11.340$ (Lei Maria da Penha), de 7 de agosto de 2006

Lei $n^{\circ} 11.525$, de 25 de setembro de 2007, que inclui o conteúdo dos direitos das crianças e dos adolescentes na Lei nº 9.394/96 (LDB)

Plano Nacional de Promoção da Cidadania e Direitos Humanos de Lésbicas, Gays, Bissexuais, Travestis e Transexuais (LGBT) (2009)

Plano Nacional de Educação (PNE) (2011-2020)

Fonte: Martins (2011, p. 20-21)

Atualmente, as diversas políticas públicas e legislações tentam resguardar crianças e adolescentes das violações dos seus direitos, 
contudo, muitos ainda vivem em um mundo cercado de violência, maustratos, exclusões e privações e acabam reproduzindo no contexto escolar comportamentos da sua vida social e familiar. De acordo com Martins (2011, p. 20-21), há um conjunto de ordenamentos legais que constituem as políticas de educação, prevenção, atenção e atendimento em relação às violências (Quadro 2). É necessário que a escola conheça todos esses recursos, a fim de amparar-se no momento de lidar com as situações de conflito no seu cotidiano.

Um marco histórico para a promoção de justiça social a crianças e jovens brasileiros foi o Estatuto da Criança e do Adolescente (ECA), Lei $\mathrm{n}^{\circ} 8.069$ de 1990, que trouxe muitos avanços e direitos, por exemplo: "O direito de toda criança brasileira à vida, à saúde, à alimentação, à dignidade, ao respeito, à liberdade e à convivência familiar e comunitária" (Brasil, 2012, art. 4). Na década de 1980, que antecede a promulgação do ECA, houve um movimento internacional para estudar, revisar e ampliar códigos referentes aos direitos da criança. No Brasil não foi diferente, e por meio de uma intensa mobilização social, que envolveu a sociedade civil, profissionais das mais diversas áreas, estudantes, ativistas, entre outros - os quais contribuíram para pensar o momento histórico em relação aos direitos das crianças -, implantou-se esse novo paradigma na construção de uma política pública para crianças e adolescentes. Fonseca, Terto Junior e Alves (2004, p. 106) assinalam que:

\begin{abstract}
Fala-se tanto nos 'direitos das crianças' a partir do ECA. Será que foi a primeira vez na história que surgiu essa noção? [...] Parece que muitas pessoas acreditam na força mágica das palavras - como se o mero fato de falar da criança enquanto 'sujeito de direitos' pudesse trazer uma mudança revolucionária na vida dos jovens brasileiros. Aprender que tais conceitos existem no mínimo desde o início do século passado traria, pelo contrário, a realização de que existe uma vasta gama de interpretações possíveis desses conceitos, e que suas consequências dependem antes de tudo da particular filosofia política que subjaz em determinado momento.
\end{abstract}

O conceito acima remete a uma importante reflexão: antes do ECA havia uma série de outras regulamentações, que ao longo do tempo foram se esgotando e necessitando de novas versões e ampliações. Desse modo, o ECA é fruto de uma trajetória histórica e procura transpor as contradições e conflitos existentes nas relações humanas. Segundo Bazílio e Kramer (2011), o Estatuto da Criança e do Adolescente introduziu mudanças significativas em relação à legislação anterior, o chamado Código de Menores, instituído em 1979.

Crianças e adolescentes passam então a ser considerados cidadãos, com direitos pessoais e sociais garantidos, desafiando os governos municipais a programarem políticas públicas, especialmente dirigidas a esse segmento. No Brasil, definitivamente substituiu-se o termo "menor" por "criança e adolescente", já que menor traz a ideia de uma pessoa sem direitos. Essa palavra foi banida do vocabulário de quem defende os 
direitos da infância, a fim de evitar relembrar o direito penal do menor e toda a carga discriminatória, por quase sempre se referir a crianças e adolescentes autores de atos infracionais:

Com o reordenamento político do país e a ampliação dos espaços de discussão sobre os direitos da população brasileira foi posta em cheque a legislação dirigida à infância e juventude, conhecida como Código de Menores. Tratava-se de um conjunto de leis que tinha a atenção dirigida apenas sobre uma parcela da população infanto-juvenil, justamente aquela oriunda das camadas mais desfavorecidas do país. O sentido geral desse código era disciplinar condutas para crianças e adolescentes pobres, que vivessem em condições precárias (os chamados "carentes") e aqueles que fossem reconhecidos pela transgressão às normas sociais (os "infratores"). Conhecida como "Doutrina da Situação Irregular", servia para discriminar e segregar crianças e adolescentes já estigmatizados por suas condições de pobreza. (Grandino, 2012).

Bazílio e Kramer (2011, p. 30) lembram-nos de que o Estatuto da Criança e do Adolescente propõe a transformação de dois grandes eixos de atendimento/educação de crianças e adolescentes:

[...] um primeiro grupo de ações denominadas "medidas protetivas", o qual busca resgatar ou dar oportunidade de correção de trajetória de vida, priorizando aquisição de direitos básicos que foram violados - realizadas em grande parte por conselhos tutelares. O segundo eixo descreve um conjunto de procedimentos denominados "medidas socioeducativas", de acordo com os quais o adolescente em conflito com a lei (anteriormente denominado de autor de ato infracional) teria possibilidade de reorganizar sua existência numa dinâmica prioritariamente educativa.

Diante das várias críticas que são mantidas sobre o ECA, a mais comum de todas refere-se à opinião de que a lei trouxe um afrouxamento dos deveres destinados a crianças e adolescentes, fazendo uma apologia aos seus direitos. Grandino (2012) contrapõe:

A leitura atenta da lei permite compreender que ali não estão artigos que fragilizam a autoridade dos adultos em relação às crianças e adolescentes, mas que o empenho necessário para garantir seus dispositivos está no interior das instituições que trabalham com essa população: a família, a escola, as organizações sociais e oficiais, entre outras. Trata-se de poder consolidar os modos condizentes aos contextos democráticos, de participação, reconhecimento de todos como sujeitos de direitos e, principalmente, de fortalecimento das instâncias de mediação. Mais ainda, trata-se de fortalecer os adultos, que carregam pesadas responsabilidades em relação aos mais novos, sem serem reconhecidos, no mais das vezes, como sujeitos de direitos também.

Mantém-se, atualmente, uma ampla discussão sobre a questão dos adolescentes em conflito com a lei, cujas infrações e crimes passam a ser realizados cada vez mais precocemente e recorrentemente, demonstrando que as medidas socioeducativas não estão dando conta de encaminhar devidamente esse grave problema social.

Tal discussão precisa ser amplamente realizada entre os vários segmentos da sociedade, para que se busquem alternativas que vão além 
do encarceramento, pois as prisões serão sempre insuficientes enquanto não se resolverem problemas sociais crônicos em nosso País.

Em relação às famílias, Digiácomo (2012) faz sua análise da seguinte maneira:

Os pais que se mostrarem omissos no cumprimento de tal DEVER estarão sujeitos a duras sanções, previstas no próprio Estatuto e legislação correlata, sempre lembrando que cabe a cada um de nós impedir que crianças e adolescentes tenham ameaçado ou violado seu DIREITO À EDUCAÇÃO, que compreende o DIREITO A RECEBER LIMITES de seus pais ou responsável, que, no entanto, não podem abusar dos meios de correção e disciplina, sob pena de incorrer no crime de maus-tratos, previsto no Código Penal (que é de 1940).

Assim, a família e a escola devem ter muita clareza do seu papel educativo, ambas devem resgatar sua autoridade, estabelecer limites e sustentar regras e princípios que regem as relações sociais, visando a uma convivência mais harmoniosa, capaz de conduzir à resolução dos conflitos. A família não pode eximir-se da sua função educativa, repassando para a escola e para os conselhos tutelares a responsabilidade de educar seus filhos. No senso comum, criou-se a ideia de que os pais não podem mais exercer autoridade sobre os seus filhos, não podem fazer exigências, impor regras, estabelecer limites.

Nesse sentido, a lei é bem clara quando afirma que a família não pode se omitir do seu papel educativo, sob pena de ser punida pelo próprio Estatuto da Criança e do Adolescente. Dessa forma, pode-se refletir que respeito, disciplina e limites se constroem e não se impõem. Se desde pequeno o bebê não mantém a convivência e não cria vínculos com seus pais, ao crescer, vai buscar na televisão, no videogame, no computador e nos amigos suprir a ausência dos pais, que estão sempre envolvidos em seus crescentes compromissos profissionais, em sua jornada de trabalho ampliada e nos demais acontecimentos sociais e culturais.

Os pais precisam reconhecer que a sua ausência não pode ser preenchida com presentes, breves passeios ao shopping ou concessões inadequadas. A verdadeira educação se inicia desde o nascimento, com o acompanhamento constante das diversas etapas de evolução da criança, para que possa se estabelecer uma relação de reciprocidade e respeito e, acima de tudo, a fim de que a família possa estar unida para enfrentar todos os desafios que a vida lhe impõe.

Dessa maneira, a participação das famílias se estende ao cotidiano escolar, pois a escola não pode ser responsabilizada, sozinha, pela educação das crianças e dos adolescentes, já que família e escola desempenham papéis complementares. Não se pode mais continuar com o dedo indicador apontado, buscando culpados para a indisciplina, a violência e o baixo rendimento escolar. Cada segmento deve responsabilizar-se por suas obrigações e, se cada um cumprir o seu papel, todos estarão juntos, como parceiros, na tarefa de educar as crianças, alunos e futuros cidadãos.

Diante da complexidade dessa temática, deve-se ter presente que educar em direitos humanos não é uma tarefa que se esgota ao final do 
ano letivo ou que permite após um bimestre fazer avaliações, atribuir notas e passar para o conteúdo seguinte. Pelo contrário, consiste em um trabalho contínuo e permanente, que deverá ser constantemente retomado, superando os modelos e prescrições tradicionais de organização curricular, de métodos, de prática docente, permitindo o trânsito do diálogo, do respeito às diferenças e da autonomia.

Para tanto, é essencial que o problema esteja claramente definido, envolvendo a análise de vários aspectos, como os conceitos de violência e indisciplina, as interpretações dos fatos fundamentados teoricamente, as concepções dos professores, as formas de organização da escola, o modo de gestão. Assim, os momentos, os espaços e as situações necessitam ser considerados e reorganizados de acordo com a lógica da equidade, do autoconhecimento e da autonomia.

Ser professor exige estar continuamente no lugar do outro, respeitando-o como ser humano e como cidadão. Quando a relação interpessoal entre professor e aluno é pautada nesses princípios, o aluno passará também a querer relacionar-se com seus professores. Neste momento de transição de paradigmas educacionais e da própria cultura, pode-se optar pela manutenção de uma educação cujo único objetivo é a transmissão de conhecimento e a disciplina é entendida como controle e regulação ou escolher uma educação cidadã, na qual o aluno é protagonista da sua trajetória, num processo de construção coletiva do saber, buscando a integralidade do ser humano.

\section{Considerações finais}

Destacou-se, ao longo do presente artigo, que o Brasil está passando por um momento de transição e modernização, exigindo que as práticas educacionais alicerçadas no conservadorismo e na tradição sejam direcionadas para novos paradigmas, que não podem prescindir da inclusão dos direitos humanos, inseridos no currículo escolar de forma inter e transdisciplinar.

Diversos documentos incluem temas como cidadania e democracia nos currículos escolares, porém há muitos desafios a serem transpostos e não se pode prescindir de reescrever a história educacional brasileira baseada nos princípios dos direitos humanos, despertando a consciência da cidadania plena e da transformação social. Progredir é crescer eticamente e muitas vezes reescrever os códigos de conduta que foram construídos pela humanidade, a fim de adequá-los à realidade contemporânea, por isso a escola cumpre um importante papel de tornar-se um meio de edificar um mundo melhor, instrumentalizando as pessoas para agirem com solidariedade e fraternidade diante dos desafios da vida.

Não se pode pensar nessa trajetória de forma individualizada: cada homem, mulher, pessoa, cidadão e professor tem seu papel a cumprir, para que a educação em direitos humanos não se confine nos 
gabinetes e em extensos documentos, sem se concretizar no cotidiano escolar. Os educadores podem se sentir sozinhos e desamparados diante desse grande desafio, pois as famílias estão cada vez mais distantes da escola, a mídia destaca de forma veemente a violência e as transgressões dos valores essenciais da humanidade, as políticas públicas parecem insuficientes para garantir a execução de projetos e programas que valorizem a cidadania e a paz. Enfim, são tantos os contrastes e as diferenças que permeiam o cotidiano escolar que, por vezes, os educadores podem sentir-se enfraquecidos e desesperançados na tarefa de colaborar para a construção de um mundo mais humano e mais justo. Entretanto, como já se afirmou ao longo do texto: a escola, por muitas vezes, constitui-se na única oportunidade de os alunos construírem atitudes, saberes, comportamentos e compromissos que levem ao exercício da paz.

Em se tratando de educação, as ações têm um peso muito maior do que os discursos, assim, a escola precisa continuamente revisar suas práticas e princípios com o propósito de garantir a vivência dos ideais e valores da cidadania, baseada na concretude de seus desafios cotidianos e na discussão constante dos seus compromissos para com a educação em direitos humanos.

\section{Referências bibliográficas}

ALENCAR, C. (Org.). Direitos mais humanos. Rio de Janeiro: Garamond, 1998.

BASÍLIO, L. C.; KRAMER, S. Infância, educação e direitos humanos. 4. ed. São Paulo: Cortez, 2011.

BOBBIO, N. A era dos direitos. Rio de Janeiro: Campus, 2004.

BRASIL. Constituição da República Federativa do Brasil de 1988.

Disponível em:<http://www.planalto.gov.br/ccivil_03/constituicao/ constituicao.htm>. Acesso em: 3 ago. 2012.

BRASIL. Lei no 8.069, de 13 de julho de 1990. Dispõe sobre o Estatuto da Criança e do Adolescente e dá outras providências. Disponível em: <http://www.planalto.gov.br/ccivil_03/leis/L8069.htm>. Acesso em: 2 ago. 2012.

BRASIL. Lei de Diretrizes e Bases da Educação Nacional - LDB: Lei nº 9394/96, que estabelece as diretrizes e bases da educação nacional. 2. ed. Brasília: Câmara dos Deputados, Coordenação de Publicações, 2001. 
BRASIL. Comitê Nacional de Educação em Direitos Humanos. Plano Nacional de Educação em Direitos Humanos. Brasília: Secretaria Especial dos Direitos Humanos, Ministério da Educação, 2003.

CANDAU, V. Experiências de educação em direitos humanos na América Latina: o caso brasileiro, 1999. Disponível em: < http://migre. me/eVOsh>. Acesso em: 07 ago. 2012.

COMPARATO, F. K. A afirmação histórica dos direitos humanos. São Paulo: Saraiva, 2007.

DALLARI, D.A. Direitos humanos e cidadania. 2.ed. São Paulo: Moderna, 2004.

DECLARAÇÃO UNIVERSAL DOS DIREITOS HUMANOS. Adotada e proclamada pela resolução 217 A (III) da Assembléia Geral das Nações Unidas em 10 de dezembro de 1948. Disponível em: <http://portal. mj.gov.br/sedh/ct/legis_intern/ddh_bib_inter_universal.htm $>$. Acesso em: 5 jul. 2012.

DIGIÁCOMO, M. J. Estatuto da criança e do adolescente: direitos X deveres. Disponível em: < http://www.mp.go.gov.br/portalweb/hp/8/ docs/estatuto_da_crianca_e_do_adolescente_-_direitos_x_deveres. pdf $>$. Acesso em: 20 jul. 2012.

FAGHERAZZI, M. A. Didática: uma perspectiva de (re)significação da prática docente. Florianópolis: UDESC/CEAD, 2002.

FONSECA, C.; TERTO JUNIOR, V.; ALVES, C. F. Antropologia, diversidade e direitos humanos. Porto Alegre: Ed. UFRGS, 2004.

FORQUIN, J.C. Escola e cultura: as bases sociais e epistemológicas do conhecimento escolar. Porto Alegre: Artes Médicas Sul, 1993.

FREIRE, P. Pedagogia do oprimido. 5.ed. Rio de Janeiro: Paz e Terra, 1978.

FREIRE, P. A importância do ato de ler: em três artigos que se completam. 3.ed. São Paulo: Cortez, 1983.

GRANDINO, P. J. Estatuto da criança e do adolescente: o sentido da Lei para as relações intergeracionais. Disponível em: < http://portal.mec. gov.br/seb/arquivos/pdf/Etica/12_junqueira.pdf>. Acesso em: 20 jul. 2012

LA TAILLE, Y. Indisciplina/disciplina: ética, moral e ação do professor. Porto Alegre: Mediação, 2005. 
MACHADO, N.J. Educação: projetos e valores. São Paulo: Escrituras, 2006.

MALDONADO, M. T. Os construtores da paz: caminhos da prevenção da violência. 2. ed. São Paulo: Moderna, 2004.

MARTINS, R. K. (Org.). Política de educação, prevenção, atenção e atendimento às violências na escola. Florianópolis: Secretaria de Estado da Educação, Diretoria de Educação Básica e Profissional, 2011.

MINAYO, M. C. S.; ASSIS, S. G. Violência e saúde na infância e adolescência: uma agenda de investigação estratégica. Cadernos de Saúde Pública, Rio de Janeiro, maio 1994. Disponível em: <http://www. scielo.br/scielo.php?pid=S0102-311X1994000500002\&script =sci_ arttext. $>$

PROJETO DE LEI. Aprova o Plano Nacional de Educação para o decênio 2011-2020 e dá outras providências. Disponível em:<http://www. camara.gov.br/sileg/integras/831421.pdf> . Acesso em: 27 abr. 2013.

SACRISTÁN, J. G.; GÓMES, A.I.P. Comprender e transformar o ensino. Porto Alegre: Artmed, 1998.

SOUSA, A. M. B. Educação biocêntrica: tecendo uma compreensão. Revista Pensamento Biocêntrico, n. 5, jan./jul. 2006. Disponível em: <http://www.pensamentobiocentrico.com.br/content/ed05_art01.php>. Acesso em: 24 jul. 2012.

SOUZA, H. Ética e cidadania. São Paulo: Moderna, 1996.

TAVARES, C. Educar em direitos humanos: o desafio da formação dos educadores numa perspectiva interdisciplinar. Disponível em: < http:// migre.me/epTmk >. Acesso em: 7 ago. 2012.

VYGOTSKY, L.S. A formação social da mente. São Paulo: Martins Fontes, 1984.

Mara Regina Zluhan, mestre em Educação e Cultura pela Universidade do Estado de Santa Catarina (Udesc), é orientadora educacional da Secretaria de Estado da Educação de Santa Catarina e professora nos cursos de graduação e pós-graduação da Faculdade Avantis, Balneário Camboriú, Santa Catarina, Brasil.

mara@redel.com.br 
Tânia Regina Raitz, doutora em Educação pela Universidade Federal do Rio Grande do Sul (UFRGS), é professora e pesquisadora no Programa de Pós-Graduação em Educação da Universidade do Vale do Itajaí (Univali), Itajaí, Santa Catarina, Brasil.

floraitz@yahoo.com.br

Recebido em 10 de junho de 2013.

Aprovado em 9 de janeiro de 2014. 